\title{
Household factors associated with infant and under-five mortality in sub-Saharan Africa countries
}

\author{
Michael Ekholuenetale ${ }^{1 *}$, Anthony Ike Wegbom², Godson Tudeme ${ }^{3}$ and Adeyinka Onikan ${ }^{4}$
}

\author{
${ }^{*}$ Correspondence: \\ mic42006@gmail.com \\ ${ }^{1}$ Department \\ of Epidemiology and Medical \\ Statistics, Faculty of Public \\ Health, College of Medicine, \\ University of Ibadan, Ibadan, \\ Nigeria \\ Full list of author information \\ is available at the end of the \\ article
}

\begin{abstract}
Background: Child mortality has become a prominent public health issue in subSaharan Africa (SSA). The mortality rates can in part be translated to how communities meet the health needs of children and address key household and environmental risk factors. Though discussions on the trends and magnitude of child mortality continue as to strategize for a lasting solution, large gap exists specifically in family characteristics associated with child death. Moreover, household dynamics of child mortality in SSA is under researched despite the fact that mortality rates remain high. This study aimed to examine the influence of household structure on child mortality in SSA.
\end{abstract}

Methods: Secondary data from birth histories in recent Demographic and Health Survey (DHS) in 35 SSA countries were used in this study. The total sample data of children born in the 5 years prior to the surveys were 384,747 births between 2008 and 2017. Unadjusted and adjusted Cox proportional hazard regression model was fitted to model infant and under-five mortality. The measure of association was hazard ratio (HR) with 95\% confidence interval (Cl). Statistical test was conducted at $p<0.05$ level of significance.

Results: Total infant mortality rates were highest in Sierra Leone (92 deaths per 1000 live births), Chad (72 deaths per 1000 live births) and Nigeria (69 deaths per 1000 live births), respectively. Furthermore, total rates of under-five mortality across 35 SSA countries were highest in Cameroon (184 deaths per 1000 live births), Sierra Leone (156 deaths per 1000 live births) and Chad (133 deaths per 1000 live births). The risk of infant mortality was higher in households of polygyny, compared with households of monogyny ( $H R=1.23 ; \mathrm{Cl} 1.16,1.29)$. Households with large number of children (3-5 and $\geq 6$ ) had higher risk of infant mortality, compared with those with 1-2 number of children. Infants from mothers with history of multiple union had $16 \%$ increase in the risk of infant mortality, compared with those from mothers from only one union $(H R=1.16 ; \mathrm{Cl} 1.09,1.24)$. Furthermore, under-five from female household headship had $10 \%$ significant reduction in the risk of mortality, compared with those from male household headship ( $\mathrm{HR}=0.90 ; \mathrm{Cl} 0.84,0.96)$. The risk of under-five mortality was higher in households of polygyny, compared with monogyny ( $\mathrm{HR}=1.33 ; \mathrm{Cl} 1.28,1.38)$. Households with large number of children ( $3-5$ and $\geq 6$ ) had higher risk of under-five mortality, compared with those with 1-2 number of children ever born. Under-five 
from mothers with history of multiple union had 30\% increase in the risk of mortality, compared with those from mothers from only one union ( $H R=1.30 ; \mathrm{Cl} 1.24,1.36)$.

Conclusion: Household structure significantly influences child mortality in SSA. Knowledge of drivers of infant and child death is crucial in health policy, programmes designs and implementation. Therefore, we suggest that policies to support strong healthy families are urgently needed to improve children's survival.

Keywords: Family structure, Infant death, Under-5 death, DHS

\section{Background}

Child mortality remains prevalent in SSA region (Burke et al. 2016; Ester et al. 2011; Kazembe et al. 2012). Population surveillance of child mortality is of a great interest to stakeholders in health system, and a key indicator of health and socioeconomic development. Globally, SSA region still accounts for the highest absolute number of under-5 deaths and the largest mortality rates (Guillot et al. 2012). Child mortality is reported at national level, particularly in resource-constrained settings, where estimates from Global Burden of Disease studies depend on national-based surveys. Nonetheless, more is yet to be known about urban vs rural spread of under-5 mortality across SSA region, pointing to key areas of evidence-based gaps in the knowledge about death occurrences (Burke et al. 2016).

Disparities exist in child mortality rates amongst family structure types (Omariba and Boyle 2007). A study reported on the role that marital status plays in predicting child survival outcome, and obtained a consistent pattern that polygyny significantly decreased the survival of infants from polygynous families (Smith-Greenaway and Trinitapoli 2014). Furthermore, infants born to unmarried mothers had higher mortality rates than those born to married mothers (Freeman and Brewer 2013). Understanding the differences in infant and child mortality rates between married and cohabiting mothers, or cohabiting and single mothers is paramount. Based on the pattern of birth outcomes and prenatal health behaviours, one might entirely conclude that infants of married or cohabiting mothers could have less of a mortality risk than infants of single mothers. An evidence-based study reported single motherhood is a risk factor of children's nutritional status and chances of survival before 5 years of age in SSA (Ntoimo and Odimegwu 2014).

Historically, large family sizes were regarded as a source of sustenance and respect in many SSA communities. Unfortunately, this exposed children to high risk of death due to economic constraints of large households, in terms of accessibility and availability of resources (Kabagenyi and Rutaremwa 2013). Children are the most vulnerable group subjected to the risk of death as a result of unfavourable household factors (Ajao et al. 2010). This can be explained by the capacity of a household to adequately meet the needs of all members been affected by household structure comprising household size, household type, place of residence amongst others. In a previous report, the influence of household structure and household economic status on the well-being of a child in SSA was established (Akinyemi et al. 2016; Omariba and Boyle 2007). The issue of household structure in relation to child survival requires adequate explanations to enhance sustainable programmes on child survival. 
The implications of changing the structure of family and what it means for the nation's children have been the subject of extensive research in recent decades (Freeman and Brewer 2013). The need to understand this relationship is underscored by the welldocumented impact of prenatal health behaviours on birth outcomes (Kabagenyi and Rutaremwa 2013). Thus, gaining an understanding of the ways in which family structure affects the healthy development of children is vital in this time of rapid changes to family life. Certainly, different family structures provide very different environments for children, but the impact that family structure has on early child health outcomes is most salient. Since family is usually the basic unit of interaction for everyone, family structure and dynamics impact child survival outcomes immensely. The family process literature describes the family as a unit that makes decisions and allocates resources to achieve goals. Family processes such as flexibility, caring communication and supervision are important factors influencing the functioning of families and the well-being of individual members (Freeman and Brewer 2013; Omariba and Boyle 2007). Household dynamics of child mortality in SSA is under researched despite the fact that mortality rates remain high. This study aimed to examine the influence of household structure on child mortality in SSA.

\section{Methods}

\section{Data source}

The pooled multi-country nationally representative DHS data from birth histories in 35 SSA countries were analysed in this study. The total sample data of children born in the 5 years prior to the surveys were 384,747 births between 2008 and 2017. DHS data for all SSA countries were retrieved from the Measure DHS online data archive after necessary approval for data use. DHS are routinely conducted every 5 years using similar methodologies and instruments across several countries. The data are in the public domain and were accessed at http://dhsprogram.com/data/available-datasets.cfm. Details of DHS data have been reported elsewhere (Corsi et al. 2012).

\section{Sampling procedure}

DHS were based on a stratified multi-stage cluster sampling technique. The stratification strategy divides the population into groups. For instance, all DHS employ a region crossed by urban-rural stratification. A multilevel stratification approach is used to divide the population into first-level strata and to subdivide the first-level strata into second-level strata, and so on. A two-level stratification in DHS is region and urban/ rural stratification. Globally, DHS are comparable household surveys that have been conducted in more than 85 countries since 1984. Though it was designed to expand on demographic, family planning, and fertility data collected in the World Fertility Surveys and Contraceptive Prevalence Surveys, DHS continue to provide an important resource for the monitoring of vital statistics and population health indicators in resource-constrained settings. It collects a wide range of objective and self-reported data with a strong focus on indicators of fertility, reproductive health, maternal and child health, mortality, nutrition and self-reported health behaviours amongst adults. Key advantages of the DHS include high-quality interviewer training, national coverage, standardised data collection procedures across countries and consistent content, allowing comparability 
across populations cross-sectionally and over time. Data from DHS facilitate epidemiological research focused on monitoring of prevalence, trends and inequalities. A variety of robust observational data analysis methods have been used, including cross-sectional designs, repeated cross-sectional designs, spatial and multilevel analyses, intra-household designs and cross-comparative analyses.

\section{Variables' selection and measurement}

\section{Outcome variables}

We recorded two response variables in this study to represent child mortality: infant and under-five mortality. Infant mortality was defined as the probability of death before the first birthday. In addition, under-five mortality was defined as the probability of death before the fifth birthday.

\section{Household characteristics}

Several household variables were included in this study.

- Sex of household headship; male/female);

- Family type: monogyny/polygyny;

- Family size based on the number of children ever born: 1-2/3-5/6+;

- Marital status: never married/in union or living with a man/formerly in union or living with a man;

- Number of union for mothers: once/more than once;

- Current residence of mothers: living with husband/partner/staying elsewhere;

- Duration of couples in union: 1 month-7 years/>7 years-14 years/>14 years21 years/> 21 years/never in union.

- Maternal educational level: None/primary/secondary/tertiary.

- Place of residence: urban/rural.

- Maternal age: 15-19/20-24/25-29/30-34/35-39/40-44/45-49.

- Household wealth quintile: For the computation of wealth index, principal components analysis (PCA) was used to assign the wealth indicator weights. This procedure assigned scores and standardised the wealth indicator variables such as floor type, wall, roof, water source, sanitation facilities, radio, electricity, television, refrigerator, cooking fuel, furniture, and number of persons per room. Thereafter, the factor coefficient scores (factor loadings) and z-scores were calculated. Finally, for each household, the indicator values were multiplied by the loadings and summed to produce the household's wealth index value. The standardised z-score was used to disentangle the overall assigned scores to poorest/poorer/middle/richer/richest (Rutstein and Staveteig 2012).

\section{Ethical consideration}

We used publicly available data in this study. The ethical procedures for data collection were the responsibility of the institutions that commissioned, funded, or managed the surveys. All DHS are approved by ICF international and Institutional Review Board (IRB) to ensure that the protocols are in compliance with the U.S. Department of Health 
and Human Services regulations for the protection of human subjects. Therefore, this study did not require further ethical approval.

\section{Data analysis}

The collinearity testing method utilised the correlation analysis to detect interdependence between variables to reduce multicollinearity. A cut-off of 0.7 was used to examine the multicollinearity known to cause major concern in multicollinearity (Midi et al. 2010). Maternal education was retained in this study as it was found to have strong association with paternal education. Other variables were retained in the model due to lack of multicollinearity. We used complex survey module ('svy') command to adjust for clustering, stratification and sampling weights. The rates of infant and under-five mortality were computed for the 5 years preceding the surveys and disaggregated by sex of children and place of residence. To explore the relationship child mortality and household factors, the unadjusted and adjusted Cox proportional hazard regression model was fitted to model infant and under-five mortality. The survival time for dead children was taken as their age at death. For children who were alive, their survival time was right censored at their current age at the time of survey. The measures of association were hazard ratio (HR) with 95\% confidence interval (CI). All statistical test was conducted at $p<0.05$ level of significance. Data were analysed using Stata version 14.0 (StataCorp, College Station, TX) (StataCorp; http://www.stata.com).

\section{Results}

In Table 1, we presented the total rates of infant and under-five mortality across 35 SSA countries. In addition, these rates were reported by the place of residence and sex of children. Total infant mortality rates were highest in Sierra Leone (92 deaths per 1000 live births), Chad (72 deaths per 1000 live births) and Nigeria (69 deaths per 1000 live births), respectively. In rural settlements with higher mortality rates; Sierra Leone (92 death per 1000 live birth), Nigeria (75 deaths per 1000 live births), Guinea (73 death per 1000 live birth), Chad and Cote d'Ivoire (72 deaths per 1000 live births) had the leading rates of infant mortality in SSA countries. Majority of male children had higher rate; Sierra Leone (98 deaths per 1000 live births), Cote d'Ivoire (88 deaths per 1000 live births), Chad (80 deaths per 1000 live births), Nigeria (74 deaths per 1000 live births) and Guinea (71 deaths per 1000 live births) had the leading infant mortality rates. Furthermore, the total rates of under-five children mortalities across 35 SSA countries were highest in Cameroon (184 deaths per 1000 live births), Sierra Leone (156 deaths per 1000 live births), Chad (133 deaths per 1000 live births), Burkina-Faso (129 deaths per 1000 live births), Nigeria (128 deaths per 1000 live births), Niger (127 deaths per 1000 live births), Guinea (123 deaths per 1000 live births), Cote d'Ivoire (108 deaths per 1000 live births) and Democratic Republic of Congo (104 deaths per 1000 live births), respectively. More so, for rural settlements and male children with higher mortality rates; these countries accounted for some of the highest under-five mortality rates. See Table 1 for details.

The summary statistics of household/family structure is presented in Table 2; here, approximately one-fifth (20.6\%) of the households had female headship. In addition, about one-quarters $(24.4 \%$ and $24.8 \%)$ of the households practiced polygyny (men 


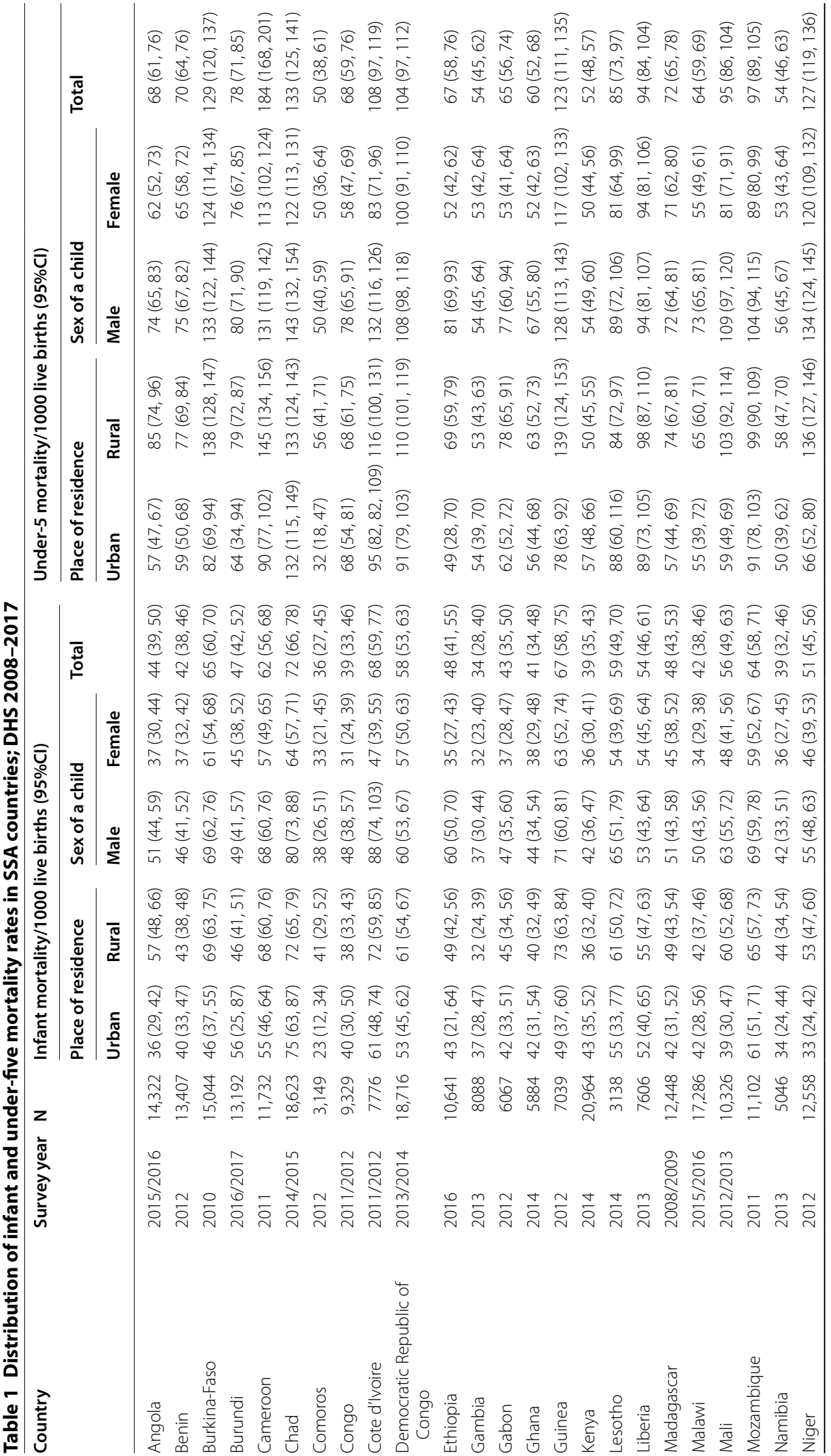




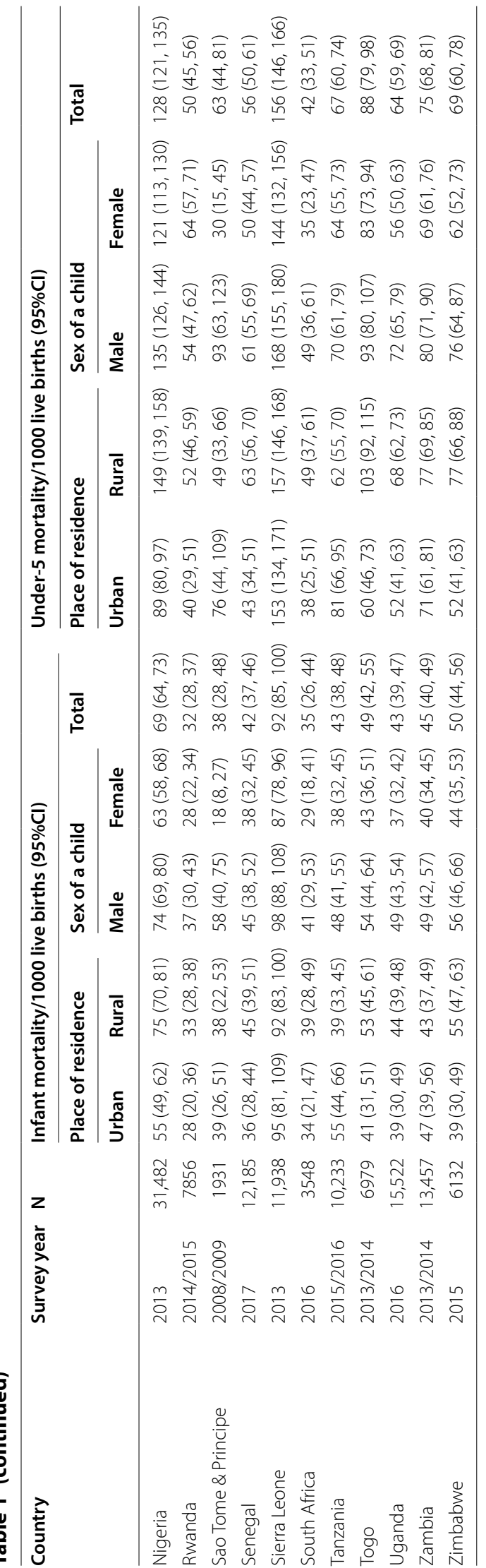


Table 2 Summary statistics for pooled data; DHS 2008-2017

\begin{tabular}{|c|c|c|}
\hline Variable & $\mathbf{N}$ & $\%$ \\
\hline \multicolumn{3}{|l|}{ Household headship } \\
\hline Male & 305,652 & 79.4 \\
\hline Female & 79,094 & 20.6 \\
\hline \multicolumn{3}{|l|}{ Family type } \\
\hline Monogyny & 242,784 & 75.6 \\
\hline Polygyny & 78,491 & 24.4 \\
\hline \multicolumn{3}{|l|}{ Family size } \\
\hline $1-2$ & 127,684 & 33.2 \\
\hline $3-5$ & 161,578 & 42.0 \\
\hline$\geq 6$ & 95,484 & 24.8 \\
\hline \multicolumn{3}{|l|}{ Marital status for mothers } \\
\hline Never married & 22,860 & 5.9 \\
\hline In union/living with a man & 335,672 & 87.3 \\
\hline Formerly in union/living with a man & 26,212 & 6.8 \\
\hline \multicolumn{3}{|l|}{ Number of unions for mothers } \\
\hline Once & 309,179 & 85.8 \\
\hline More than once & 51,188 & 14.2 \\
\hline \multicolumn{3}{|l|}{ Current residence of mother } \\
\hline Living with husband/partner & 280,723 & 86.3 \\
\hline Staying elsewhere & 44,747 & 13.7 \\
\hline \multicolumn{3}{|l|}{ Duration of couple in union } \\
\hline 1 month-7 years & 120,187 & 33.2 \\
\hline$>7$ years -14 years & 126,387 & 34.9 \\
\hline$>14$ years -21 years & 78,382 & 21.7 \\
\hline$>21$ years & 36,758 & 10.2 \\
\hline Never in union & 170 & 0.1 \\
\hline \multicolumn{3}{|l|}{ Household wealth quintiles } \\
\hline Poorest & 98,297 & 25.6 \\
\hline Poorer & 84,607 & 22.0 \\
\hline Middle & 75,708 & 19.7 \\
\hline Richer & 67,919 & 17.6 \\
\hline Richest & 58,215 & 15.1 \\
\hline \multicolumn{3}{|l|}{ Mother's educational level } \\
\hline No formal education & 159,327 & 41.4 \\
\hline Primary & 134,113 & 34.9 \\
\hline Secondary & 81,467 & 21.2 \\
\hline Higher & 9788 & 2.5 \\
\hline \multicolumn{3}{|l|}{ Place of residence } \\
\hline Urban & 114,475 & 29.8 \\
\hline Rural & 270,271 & 70.2 \\
\hline \multicolumn{3}{|l|}{ Maternal age } \\
\hline $15-19$ & 24,514 & 6.4 \\
\hline $20-24$ & 87,151 & 22.7 \\
\hline $25-29$ & 103,929 & 27.0 \\
\hline $30-34$ & 80,195 & 20.8 \\
\hline $35-39$ & 54,946 & 14.3 \\
\hline $40-44$ & 26,038 & 6.8 \\
\hline $45-49$ & 7973 & 2.1 \\
\hline
\end{tabular}


Table 2 (continued)

\begin{tabular}{lcr}
\hline Variable & N & $\%$ \\
\hline Child status & & \\
Dead & 25,174 & 6.5 \\
Alive & 359,572 & 93.5 \\
\hline
\end{tabular}

having more than one wife at a time) and have at least 6 children ever born. However, approximately one-third (33.2\%) of households have at most 2 children ever born. Whilst $5.9 \%$ of women were never married, about $6.8 \%$ reported formerly in union, others were currently in union/living with a man (87.3\%). Results showed that about $14.2 \%$ of women had been in more than one union and approximately $13.7 \%$ currently living alone (staying elsewhere). There were disparities in the duration of couples in union and this varied between 1 month-7 years and above 21 years in union. About $41.4 \%$ of women had no formal education, whilst only $2.5 \%$ had higher education. Approximately, $70.2 \%$ dwell in rural residence and disparities existed across maternal age categories. Furthermore, about $93.5 \%$ of under-five children were alive at the time of the survey. See Table 2 for the details.

Multivariable Cox Proportional Hazard model was used to examine the variables of household structure with infant mortality. The risk of infant mortality was higher in households of polygyny, compared with households of monogyny $(\mathrm{HR}=1.23$; CI $1.16,1.29)$. Households with large number of children $(3-5$ and $\geq 6)$ had higher risk of infant mortality, compared with those with 1-2 number of children ever born. Furthermore, infants from mothers with history of multiple unions had 16\% increase in the risk of infant mortality, compared with those from mothers from only one union (HR $=1.16$; CI 1.09, 1.24). Children from households with longer duration in union, high household wealth and maternal education had reduction in the risk of infant mortality, respectively. See Table 3 for the details.

In Table 4, we presented the results of multivariable Cox model used to examine variables of household structure for under-five mortality. The under-five from female household headship had $10 \%$ significant reduction in the risk of mortality, compared with male household headship ( $H R=0.90$; CI $0.84,0.96)$. On the other hand, the risk of under-five mortality was higher in households of polygyny, compared with households of monogyny ( $\mathrm{HR}=1.33$; CI 1.28, 1.38). Households with large number of children (3-5 and $\geq 6$ ) had higher risk of under-five mortality, compared with those with 1-2 number of children ever born. In addition, under-five children from mothers with history of multiple union had $30 \%$ increase in the risk mortality, compared with those from mothers from only one union $(\mathrm{HR}=1.30$; $\mathrm{CI}$ $1.24,1.36)$. Children from households with longer duration in union, high household wealth, maternal education and advanced maternal age had reduction in the risk of under-five mortality, respectively. There was increased risk of under-five mortality in rural residence, when compared with the urban $(H R=1.07$; CI 1.01, 1.12). See Table 4 for details. 
Table 3 Household factors associated with infant mortality in SSA; DHS 2008-2017

\begin{tabular}{|c|c|c|c|c|}
\hline \multirow[t]{2}{*}{ Variable } & \multicolumn{2}{|l|}{ Model I } & \multicolumn{2}{|l|}{ Model II } \\
\hline & $\mathrm{HR}(95 \% \mathrm{Cl})$ & $\mathbf{P}$ & $\mathrm{HR}(95 \% \mathrm{Cl})$ & $\mathbf{P}$ \\
\hline \multicolumn{5}{|l|}{ Household headship } \\
\hline Male & 1.00 & & & \\
\hline Female & $0.98(0.93,1.03)$ & 0.435 & - & - \\
\hline \multicolumn{5}{|l|}{ Family type } \\
\hline Monogyny & 1.00 & & 1.00 & \\
\hline Polygyny & $1.45(1.37,1.52)$ & $<0.001^{*}$ & $1.23(1.16,1.29)$ & $<0.001^{*}$ \\
\hline \multicolumn{5}{|l|}{ Family size } \\
\hline $1-2$ & 1.00 & & 1.00 & \\
\hline $3-5$ & $1.59(1.51,1.68)$ & $<0.001^{*}$ & $1.74(1.61,1,90)$ & $<0.001^{*}$ \\
\hline$\geq 6$ & $2.27(2.15,2.40)$ & $<0.001^{*}$ & $2.54(2.27,2.83)$ & $<0.001^{*}$ \\
\hline \multicolumn{5}{|l|}{ Marital status for mothers } \\
\hline Never married & 1.00 & & 1.00 & \\
\hline In union/living with a man & $1.49(1.35,1.64)$ & $<0.001^{*}$ & $\mathrm{n} / \mathrm{a}$ & \\
\hline Formerly in union/living with a man & $2.17(1.92,2.45)$ & $<0.001^{*}$ & $\mathrm{n} / \mathrm{a}$ & \\
\hline \multicolumn{5}{|l|}{ Number of unions for mothers } \\
\hline Once & 1.00 & & 1.00 & \\
\hline More than once & $1.33(1.25,1.41)$ & $<0.001^{*}$ & $1.16(1.09,1.24)$ & $<0.001^{*}$ \\
\hline \multicolumn{5}{|l|}{ Current residence of mother } \\
\hline Living with husband/partner & 1.00 & & 1.00 & \\
\hline Staying elsewhere & $0.90(0.84,0.96)$ & $0.002^{*}$ & $0.97(0.90,1.04)$ & 0.416 \\
\hline \multicolumn{5}{|l|}{ Duration of couple in union } \\
\hline 1 month-7 years & 1.00 & & 1.00 & \\
\hline$>7$ years -14 years & $1.34(1.27,1.41)$ & $<0.001^{*}$ & $0.89(0.82,0.97)$ & $0.006^{*}$ \\
\hline$>14$ years -21 years & $1.49(1.40,1.59)$ & $<0.001^{*}$ & $0.82(0.74,0.92)$ & $0.001^{*}$ \\
\hline$>21$ years & $2.13(1.98,2.29)$ & $<0.001^{*}$ & $0.90(0.78,1.04)$ & 0.147 \\
\hline Never in union & $0.26(0.04,1.85)$ & 0.178 & $0.31(0.04,2.17)$ & 0.236 \\
\hline \multicolumn{5}{|l|}{ Household wealth quintiles } \\
\hline Poorest & 1.00 & & 1.00 & \\
\hline Poorer & $1.02(0.96,1.08)$ & 0.565 & $1.06(0.99,1.14)$ & 0.061 \\
\hline Middle & $0.93(0.87,0.99)$ & $0.027^{*}$ & $1.00(0.93,1.07)$ & 0.970 \\
\hline Richer & $0.82(0.77,0.88)$ & $<0.001^{*}$ & $0.92(0.85,0.99)$ & $0.028^{*}$ \\
\hline Richest & $0.66(0.61,0.71)$ & $<0.001^{*}$ & $0.82(0.74,0.90)$ & $<0.001^{*}$ \\
\hline \multicolumn{5}{|l|}{ Mother's educational level } \\
\hline No formal education & 1.00 & & 1.00 & \\
\hline Primary & $0.79(0.75,0.83)$ & $<0.001^{*}$ & $0.88(0.83,0.93)$ & $<0.001^{*}$ \\
\hline Secondary & $0.60(0.56,0.64)$ & $<0.001^{*}$ & $0.82(0.76,0.89)$ & $<0.001^{*}$ \\
\hline Higher & $0.38(0.32,0.47)$ & $<0.001^{*}$ & $0.64(0.50,0.81)$ & $<0.001^{*}$ \\
\hline \multicolumn{5}{|l|}{ Place of residence } \\
\hline Urban & 1.00 & & 1.00 & \\
\hline Rural & $1.28(1.22,1.35)$ & $<0.001^{*}$ & $1.03(0.96,1.10)$ & 0.372 \\
\hline \multicolumn{5}{|l|}{ Maternal age } \\
\hline $15-19$ & 1.00 & & 1.00 & \\
\hline $20-24$ & $1.32(1.21,1.45)$ & $<0.001^{*}$ & $1.04(0.93,1.16)$ & 0.491 \\
\hline $25-29$ & $1.48(1.36,1.62)$ & $<0.001^{*}$ & $0.90(0.80,1.02)$ & 0.102 \\
\hline $30-34$ & $1.56(1.42,1.71)$ & $<0.001^{*}$ & $0.80(0.70,0.92)$ & $0.001^{*}$ \\
\hline $35-39$ & $1.76(1.59,1.93)$ & $<0.001^{*}$ & $0.80(0.69,0.93)$ & $0.004^{*}$ \\
\hline $40-44$ & $2.43(2.17,2.71)$ & $<0.001^{*}$ & $0.94(0.79,1.12)$ & 0.492 \\
\hline $45-49$ & $3.58(3.08,4.17)$ & $<0.001^{*}$ & $1.32(1.07,1.63)$ & $0.011^{*}$ \\
\hline
\end{tabular}


Table 3 (continued)

Model I Crude model, Model II Adjusted model, $n / a$ not estimated due to small sample, $H R$ hazard ratio, $\mathrm{Cl}$ Confidence Interval

*Significant at $\mathrm{p}<0.05$

\section{Discussion}

In this study, we examined the differences in infant and under-five mortality across SSA countries, by place of residence and sex of children. In addition, we investigated the association between household structure and child mortality using multivariable Cox models. Based on the results, SSA countries showed high rates of infant and under-five mortality. Comparing with the third Sustainable Development Goal (SDG-3) of ending preventable deaths of newborns and children under 5 years of age, with all countries aiming to reduce under- 5 mortality to a minimum of 25 per 1000 live births by 2030 (Rosa, 2017); the findings showed that most SSA countries still have high child mortality. The rates appear to arise largely from household structure. Poor household structure could adversely increase the risk of child mortality. The findings are consistent with reports from a previous study (Guillot et al. 2012).

There was reduction in the risk of under-five mortality in female-headed households. Similar findings have been reported by Adhikari and Podhisita in which female-headed household had reduction in the risk of under-five mortality (Adhikari and Podhisita 2010). This study found that amongst many other factors, household headship was a strong determinant of under-five mortality. This shows that women's autonomy and empowerment through improved maternal literacy, ability to decide independently on the use of maternal healthcare services including paediatric care, could help to reduce under-five mortality. Furthermore, we found reduction in the risk of infant and underfive mortality with longer marriage duration. This is contrary to a previous report, which found the proportions of child death increased with marital duration (Islam, Rahman, Rahman 2013). This could be due to the fact that the average parities reported from the study increased monotonically with the duration of marriage. Moreover, women with longer duration in marriage may have more knowledge to prevent preterm birth complications, pneumonia, interpartum-related events, neonatal sepsis, diarrhoea, malaria, severe undernutrition amongst other factors which could contribute to high risk of child mortality.

High household wealth status, maternal education and advanced maternal age were found to significantly reduce the risk of child mortality. This is consistent with reports from previous studies which found maternal education and improved household wealth index to be associated with reduction in the risk of child death (Adebowale et al. 2012; Yaya et al. 2017). Notably, mothers' socioeconomic status, specifically education and wealth status could be linked with quality health practices and proper health behaviour including childcare and optimal feeding habits. The socioeconomic status of a mother could modify her role in the family and equip her in taking measures to improve child's health by adequately using modern and innovative health services (Buor, 2003).

In addition, children within polygynous marriages were found to have higher risk of infant and under-five mortality, when compared with children from monogynous families. The findings from previous studies supported the arguments that child death is associated to marriage types (Arthi and Fenske 2018; Lawson and Gibson 
Table 4 Household factors associated with under-five mortality in SSA; DHS 2008-2017

\begin{tabular}{|c|c|c|c|c|}
\hline \multirow[t]{2}{*}{ Variable } & \multicolumn{2}{|l|}{ Model III } & \multicolumn{2}{|l|}{ Model IV } \\
\hline & $\mathrm{HR}(95 \% \mathrm{Cl})$ & $\mathbf{P}$ & $\mathrm{HR}(95 \% \mathrm{Cl})$ & $\mathbf{P}$ \\
\hline \multicolumn{5}{|l|}{ Household headship } \\
\hline Male & 1.00 & & 1.00 & \\
\hline Female & $0.88(0.85,0.92)$ & $<0.001^{*}$ & $0.90(0.84,0.96)$ & $0.002^{*}$ \\
\hline \multicolumn{5}{|l|}{ Family type } \\
\hline Monogyny & 1.00 & & 1.00 & \\
\hline Polygyny & $1.51(1.46,1.57)$ & $<0.001^{*}$ & $1.33(1.28,1.38)$ & $<0.001^{*}$ \\
\hline \multicolumn{5}{|l|}{ Family size } \\
\hline $1-2$ & 1.00 & & 1.00 & \\
\hline $3-5$ & $1.29(1.24,1.35)$ & $<0.001^{*}$ & $1.83(1.73,1.95)$ & $<0.001^{*}$ \\
\hline$\geq 6$ & $1.78(1.71,1.86)$ & $<0.001^{*}$ & $3.28(3.03,3.55)$ & $<0.001^{*}$ \\
\hline \multicolumn{5}{|l|}{ Marital status for mothers } \\
\hline Never married & 1.00 & & 1.00 & \\
\hline In union/living with a man & $1.25(1.16,1.36)$ & $<0.001^{*}$ & $\mathrm{n} / \mathrm{a}$ & \\
\hline Formerly in union/living with a man & $1.41(1.28,1.55)$ & $<0.001^{*}$ & $\mathrm{n} / \mathrm{a}$ & \\
\hline \multicolumn{5}{|l|}{ Number of unions for mothers } \\
\hline Once & 1.00 & & 1.00 & \\
\hline More than once & $1.33(1.28,1.39)$ & $<0.001^{*}$ & $1.30(1.24,1.36)$ & $<0.001^{*}$ \\
\hline \multicolumn{5}{|l|}{ Current residence of mother } \\
\hline Living with husband/partner & 1.00 & & 1.00 & \\
\hline Staying elsewhere & $0.94(0.89,0.99)$ & $0.015^{*}$ & $1.04(0.97,1.11)$ & 0.271 \\
\hline \multicolumn{5}{|l|}{ Duration of couple in union } \\
\hline 1 month -7 years & 1.00 & & 1.00 & \\
\hline$>7$ years -14 years & $1.04(1.00,1.09)$ & $0.045^{*}$ & $0.78(0.73,0.82)$ & $<0.001^{*}$ \\
\hline$>14$ years -21 years & $1.08(1.03,1.13)$ & $0.001^{*}$ & $0.66(0.61,0.71)$ & $<0.001^{*}$ \\
\hline$>21$ years & $1.27(1.21,1.35)$ & $<0.001^{*}$ & $0.72(0.65,0.80)$ & $<0.001^{*}$ \\
\hline Never in union & $0.94(0.39,2.26)$ & 0.890 & $0.87(0.36,2.09)$ & 0.756 \\
\hline \multicolumn{5}{|l|}{ Household wealth quintiles } \\
\hline Poorest & 1.00 & & 1.00 & \\
\hline Poorer & $0.98(0.94,1.03)$ & 0.465 & $1.02(0.97,1.07)$ & 0.419 \\
\hline Middle & $0.86(0.82,0.91)$ & $<0.001^{*}$ & $0.93(0.88,0.98)$ & $0.007^{*}$ \\
\hline Richer & $0.77(0.73,0.81)$ & $<0.001^{*}$ & $0.89(0.0 .84,0.94)$ & $<0.001^{*}$ \\
\hline Richest & $0.56(0.0 .53,0.60)$ & $<0.001^{*}$ & $0.77(0.71,0.83)$ & $<0.001^{*}$ \\
\hline \multicolumn{5}{|l|}{ Mother's educational level } \\
\hline No formal education & 1.00 & & 1.00 & \\
\hline Primary & $0.74(0.71,0.77)$ & $<0.001^{*}$ & $0.78(0.75,0.82)$ & $<0.001^{*}$ \\
\hline Secondary & $0.57(0.54,0.59)$ & $<0.001^{*}$ & $0.74(0.70,0.79)$ & $<0.001^{*}$ \\
\hline Higher & $0.27(0.23,32)$ & $<0.001^{*}$ & $0.52(0.42,0.64)$ & $<0.001^{*}$ \\
\hline \multicolumn{5}{|l|}{ Place of residence } \\
\hline Urban & 1.00 & & 1.00 & \\
\hline Rural & $1.39(1.33,1.44)$ & $<0.001^{*}$ & $1.07(1.01,1.12)$ & $0.013^{*}$ \\
\hline \multicolumn{5}{|l|}{ Maternal age } \\
\hline $15-19$ & 1.00 & & 1.00 & \\
\hline $20-24$ & $0.75(0.70,0.81)$ & $<0.001^{*}$ & $0.63(0.58,0.69)$ & $<0.001^{*}$ \\
\hline $25-29$ & $0.73(0.68,0.79)$ & $<0.001^{*}$ & $0.51(0.46,0.56)$ & $<0.001^{*}$ \\
\hline $30-34$ & $0.71(0.66,0.76)$ & $<0.001^{*}$ & $0.41(0.37,0.45)$ & $<0.001^{*}$ \\
\hline $35-39$ & $0.74(0.68,0.80)$ & $<0.001^{*}$ & $0.35(0.31,0.40)$ & $<0.001^{*}$ \\
\hline $40-44$ & $0.78(0.71,0.85)$ & $<0.001^{*}$ & $0.32(0.28,0.37)$ & $<0.001^{*}$ \\
\hline $45-49$ & $0.97(0.87,1.09)$ & 0.645 & $0.37(0.32,0.44)$ & $<0.001^{*}$ \\
\hline
\end{tabular}


Table 4 (continued)

Model III Crude model, Model IV Adjusted model, $n$ /a not estimated due to small sample, $H R$ hazard ratio; Cl Confidence Interval

*Significant at $\mathrm{p}<0.05$

2018; Omariba and Boyle 2007; Smith-Greenaway and Trinitapoli 2014; Wagner and Rieger, 2015). Similarly, history of mothers' involvement in multiple union was found to be associated with increased risk of child mortality. Also, this is consistent with report from a previous study (Arntzen et al. 1996). In general, there is no doubt that polygyny and history of involvement in multiple unions by mothers could be closely connected to increased number of children ever born, which was also found to be associated with higher risk of child mortality. This is in line with previous findings (Kabagenyi and Rutaremwa 2013; Sonneveldt et al. 2013). The major pathway by which polygyny is known to negatively influence child survival is through resource dilution, with the assumption that polygyny leads to a greater number of children to support on a limited family budget. Based on this, there is a competing paradigm that polygyny impairs the survival chances of children. Polygyny and high parity can be linked with high child mortality via resource constraints, paternal investment and selectivity. The resource constraint is premised on the notion that usually large households are associated with low resource per head which adversely impacts on child health and survival.

Furthermore, the resource constraint in family resources for the upkeep of children may lead to poor living conditions which could possibly increase the vulnerability of children to diseases and subsequently death. The lack of resources can also limit access to modern healthcare particularly with the cash-and-carry system operated in several SSA countries. The large family size associated with the foregoing could practically reduce parent-child emotional attachments, which is crucial in promoting active childcare. The implication is that children from large family household's size may be less catered for, more vulnerable and consequently exposed to higher risk of death. In addition, rural place of residence was found to be associated with higher under-five mortality. The urban-rural differentials have previously been identified in child mortality (Gruebner et al. 2015; van De Poel et al. 2009; Yaya et al. 2017). This could be explained in terms of family poverty and consequently inaccessibility of paediatric healthcare services. Conventionally, rural children have poor access to healthcare services utilisation; as such early detection of abnormalities for appropriate management is unlikely. Furthermore, higher child mortality rates in rural areas are mainly derived from the socioeconomically disadvantaged household characteristics. Safe source of drinking water and improved sanitation system which are key contributors of healthy living are commonly lacking in rural areas.

The findings from this study have unravelled the relationship between household structure and child mortality in SSA. The policy implication of the findings is that concerted efforts of social welfare intervention towards household structure improvement could serve as a panacea for child mortality by operating through either socioeconomic status or fertility-related behaviour. For instance, household socioeconomic status determined the children nutrition patterns (Ekholuenetale et al. 2020). No doubt, the time and resources available for a child's care are assumed to be affected by household structure or family 
characteristics (Akinyemi et al. 2013). Therefore, positive changes in household structure can largely be promoted by family involvement in social welfare intervention.

\section{Strength and limitation}

This study utilised nationally representative multi-country data collected via standardised questionnaires to ensure similarities across geographies in SSA countries and to strengthen the evidence base. A major limitation for this study is the cross-sectional design, which makes exploration of the pathway of household characteristics on child survival difficult. Furthermore, the categories used for household relationship structure from which household type was derived did not permit exploration of the effect of inter-generational households. Caution must be taken in making comparisons of mortality across countries as the data were collected in different years.

\section{Conclusion}

In this study, our focus was to examine the impact of the household structure on infant and under-five mortality in SSA countries. The findings suggest that polygyny, large family size or increased number of children ever born, history of mothers' involvement in multiple union and rural residence were associated with the risk of child mortality. Conversely, female household headship, long duration in union, maternal education, and improved household wealth status were associated with reduction in the risk of infant and under-five mortality. In light of the above, we suggest that healthcare programmes and policies should be designed specifically to encourage healthy family structure. In addition, policies to support strong healthy families would help to intervene in the areas which likely connect family structure to children's outcomes, including parental life style and practices. In addition, the allocation of funds under parenthood, marriage and family life should focus on programmes to improve social support networks.

\section{Acknowledgements}

The authors appreciate the MEASURE DHS project for the approval and access to the original data.

\section{Authors' contributions}

ME conceived and designed the study, performed data analysis and wrote the results; AIW, GT, and AO contributed to the review of literature, discussion of the findings and critically reviewed the manuscript for its intellectual content. ME had the responsibility to submit the manuscript. All authors read and approved the final manuscript.

\section{Funding}

This research received no grant from any funding agency in the public, commercial or not-for-profit sectors.

\section{Availability of data and materials}

Data for this study were sourced from Demographic and Health surveys (DHS) and available in http://dhsprogram.com/ data/available-datasets.cfm.

\section{Competing interests}

The authors declare that the research was conducted in the absence of any commercial or financial relationships that could be construed as a potential conflict of interest.

\section{Author details}

${ }^{1}$ Department of Epidemiology and Medical Statistics, Faculty of Public Health, College of Medicine, University of Ibadan, Ibadan, Nigeria. ${ }^{2}$ Department of Mathematics, Rivers State University, Port Harcourt, Nigeria. ${ }^{3}$ School of Medicine, College of Medical Sciences, University of Benin, Benin City, Nigeria. ${ }^{4}$ Program Management Unit, Management Sciences for Health, Abuja, Nigeria.

Received: 8 May 2019 Accepted: 23 July 2020

Published online: 03 August 2020 
References

Adebowale, A. S., Yusuf, B. O., \& Fagbamigbe, A. F. (2012). Survival probability and predictors for woman experience childhood death in Nigeria: "Analysis of north-south differentials". BMC Public Health, 12, 430. https://doi. org/10.1186/1471-2458-12-430.

Adhikari, R., \& Podhisita, C. (2010). Household headship and child death: evidence from Nepal. BMC International Health and Human Rights, 10, 13.

Ajao, K., Ojofeitimi, E., Adebayo, A., Fatusi, A., \& Afolabi, O. (2010). Influence of family size, household food security status, and child care practices on the nutritional status of under-five children in lle-lfe, Nigeria. African Journal of Reproductive Health, 14(4 Spec no.), 117-126.

Akinyemi, J. O., Bamgboye, E. A., \& Ayeni, O. (2013). New trends in under-five mortality determinants and their effects on child survival in Nigeria: A review of childhood mortality data from 1990-2008. African Population Stud. https://doi. org/10.11564/27-1-5

Akinyemi, J. O., Chisumpa, V. H., \& Odimegwu, C. O. (2016). Household structure, maternal characteristics and childhood mortality in rural sub-Saharan Africa. Rural Remote Health, 16(2), 3737.

Arntzen, A., Moum, T., Magnus, P., \& Bakketeig, L. S. (1996). Marital status as a risk factor for fetal and infant mortality. Scand J Social Med, 24(1), 36-42.

Arthi, V., \& Fenske, J. (2018). Polygamy and child mortality: historical and modern evidence from Nigeria's lgbo. Rev Econ Household, 16(1), 97-141. https://doi.org/10.1007/s11150-016-9353-x.

Buor, D. (2003). Mothers' education and childhood mortality in Ghana. Health Policy, 64(3), 297-309.

Burke, M., Heft-Neal, S., \& Bendavid, E. (2016). Sources of variation in under-5 mortality across sub-Saharan Africa: a spatial analysis. Lancet Global Health, 4(12), e936-e945. https://doi.org/10.1016/S2214-109X(16)30212-1.

Corsi, D. J., Neuman, M., Finlay, J. E., \& Subramanian, S. (2012). Demographic and health surveys: a profile. Int J Epidemiol, 41(6), 1602-1613. https://doi.org/10.1093/ije/dys184.

Ekholuenetale, M., Tudeme, G., Onikan, A., \& Ekholuenetale, C. E. (2020). Socioeconomic inequalities in hidden hunger, undernutrition, and overweight among under-five children in 35 sub-Saharan Africa countries. J Egyptian Public Health Assoc, 95(1), 9. https://doi.org/10.1186/s42506-019-0034-5.

Ester, P. V., Torres, A., Freire, J. M., Hernández, V., \& Gil, Á. (2011). Factors associated to infant mortality in Sub-Saharan Africa. J Public Health Afr. https://doi.org/10.4081/jphia.2011.e27.

Freeman, L. L., \& Brewer, M. (2013). Family Matters: Links Between Family Structure and Early Child Health. Family Matters, 25.

Gruebner, O., Lautenbach, S., Khan, M. M. H., Kipruto, S., Epprecht, M., \& Galea, S. (2015). Place of Residence Moderates the Risk of Infant Death in Kenya: evidence from the Most Recent Census 2009. PLoS ONE, 10(10), e0139545. https://doi. org/10.1371/journal.pone.0139545.

Guillot, M., Gerland, P., Pelletier, F., \& Saabneh, A. (2012). Child mortality estimation: a global overview of infant and child mortality age patterns in light of new empirical data. Plos Medicine, 9(8), e1001299. https://doi.org/10.1371/journ al.pmed.1001299.

Islam, R., Rahman, M., \& Rahman, O. (2013). Estimation of childhood mortality in Bangladesh: indirect approach. App/ Math, $3(2), 61-69$.

Kabagenyi, A., \& Rutaremwa, G. (2013). The effect of household characteristics on child mortality in Uganda. Am J Sociol Res, $3(1), 1-5$.

Kazembe, L., Clarke, A., \& Kandala, N.-B. (2012). Childhood mortality in sub-Saharan Africa: cross-sectional insight into smallscale geographical inequalities from Census data. BrMed J Open, 2(5), e001421. https://doi.org/10.1136/bmjopen-2012001421

Lawson, D., \& Gibson, M. A. (2018). Polygynous marriage and child health in sub-Saharan Africa: what is the evidence for harm? Demographic Res, 39, 177-208. https://doi.org/10.4054/DemRes.2018.39.6.

Midi, H., Sarkar, S. K., \& Rana, S. (2010). Collinearity diagnostics of binary logistic regression model. J Interdiscip Math, 13(3), 253-267. https://doi.org/10.1080/09720502.2010.10700699.

Ntoimo, L. F., \& Odimegwu, C. O. (2014). Health effects of single motherhood on children in sub-Saharan Africa: A crosssectional study. BMC Public Health. https://doi.org/10.1186/1471-2458-14-1145.

Omariba, D. W. R., \& Boyle, M. H. (2007). Family structure and child mortality in sub-saharan Africa: cross-national effects of polygyny. J Marriage Family, 69(2), 528-543. https://doi.org/10.1111/j.1741-3737.2007.00381.x.

Rosa, W. (Ed.). (2017). Transforming Our World: The 2030 Agenda for Sustainable Development. In A New Era in Global Health. Springer Publishing Company. https://doi.org/10.1891/9780826190123.ap02

Rutstein, S. O., \& Staveteig, S. (2014). Making the demographic and health surveys wealth index comparable. DHS methodological reports No. 9. Rockville, Maryland, USA: ICF International.

Smith-Greenaway, E., \& Trinitapoli, J. (2014). Polygynous contexts, family structure, and infant mortality in sub-saharan Africa. Demography, 51(2), 341-366. https://doi.org/10.1007/s13524-013-0262-9.

Sonneveldt, E., DeCormier Plosky, W., \& Stover, J. (2013). Linking high parity and maternal and child mortality: what is the impact of lower health services coverage among higher order births? BMC Public Health, 13(Suppl 3), S7. https://doi. org/10.1186/1471-2458-13-S3-S7.

Van De Poel, E., O'donnell, O., \& Van Doorslaer, E. (2009). What explains the rural-urban gap in infant mortality: household or community characteristics? Demography, 46(4), 827-850.

Wagner, N., \& Rieger, M. (2015). Polygyny and child growth: evidence from twenty-six African Countries. Feminist Econ, 21(2), 105-130. https://doi.org/10.1080/13545701.2014.927953

Yaya, S., Ekholuenetale, M. Tudeme, G., Vaibhav, S., Bishwajit, G., \& Kadio, B. (2017). Prevalence and determinants of childhood mortality in Nigeria. BMC Public Health. https://doi.org/10.1186/s12889-017-4420-7.

\section{Publisher's Note}

Springer Nature remains neutral with regard to jurisdictional claims in published maps and institutional affiliations. 